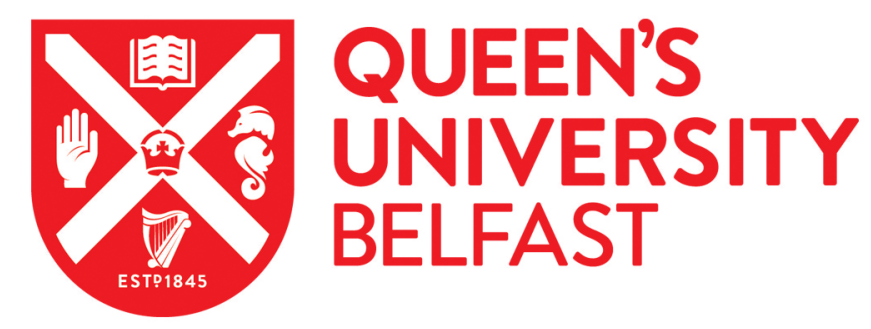

\title{
Comment on "The Critical evaluation of in situ probe techniques for catalytic honeycomb monoliths" by Hettel et al.
}

Goguet, A., Partridge, W. P., Aiouche, F., Hardacre, C., Morgan, K., Stere, C-E., \& Sa, J. (2014). Comment on "The Critical evaluation of in situ probe techniques for catalytic honeycomb monoliths" by Hettel et al. Catalysis Today, 236(1), 206-208. https://doi.org/10.1016/j.cattod.2014.02.034

Published in:

Catalysis Today

Document Version:

Peer reviewed version

Queen's University Belfast - Research Portal:

Link to publication record in Queen's University Belfast Research Portal

Publisher rights

Copyright $\odot 2014$ Elsevier B.V. All rights reserved.

This is the author's version of a work that was accepted for publication in Catalysis Today. Changes resulting from the publishing process, such as peer review, editing, corrections, structural formatting, and other quality control mechanisms may not be reflected in this document. Changes may have been made to this work since it was submitted for publication. A definitive version was subsequently published in Catalysis Today, Volume 236, Part B, 1 November 2014, DOI: 10.1016/j.cattod.2014.02.034.

\section{General rights}

Copyright for the publications made accessible via the Queen's University Belfast Research Portal is retained by the author(s) and / or other copyright owners and it is a condition of accessing these publications that users recognise and abide by the legal requirements associated with these rights.

Take down policy

The Research Portal is Queen's institutional repository that provides access to Queen's research output. Every effort has been made to ensure that content in the Research Portal does not infringe any person's rights, or applicable UK laws. If you discover content in the Research Portal that you believe breaches copyright or violates any law, please contact openaccess@qub.ac.uk. 
Comment on "The Critical evaluation of in situ probe techniques for catalytic honeycomb monoliths" by Hettel et al.

Farid Aiouche ${ }^{1,2}$, Alexandre Goguet ${ }^{1 *}$, Christopher Hardacre ${ }^{1}$, Kevin Morgan ${ }^{1}$, William P. Partridge $^{3^{*}}$, Jacinto Sá ${ }^{4}$, Cristina Stere ${ }^{1}$

${ }^{1}$ CenTACat, School of Chemistry and Chemical Engineering, Queen's University Belfast, Stranmillis Road, Belfast BT9 5AG, U.K.

${ }^{2}$ Engineering Department, Lancaster University, LA1 4YR, Lancaster, U.K.

${ }^{3}$ Fuels, Engines and Emissions Research Center, Oak Ridge National Laboratory. P.O. Box 2008, MS-6472, Oakridge, TN, 37831-6472, USA

${ }^{4}$ Laboratory for Catalysis and Sustainable Chemistry, Paul Scherrer Institute, 5232 Villigen PSI, Switzerland

*corresponding authors: a.goguet@qub.ac.uk; partridgewp@ornl.gov

Recently, Hettel et al. have investigated the invasiveness of the probes used in spatial resolution techniques which rely on in-situ sampling at various axial locations within a monolith such as the SpaciMS, using a comparison of experiments with CFD modelling [1]. The paper is very interesting as it consolidates recent publications on the promising use of sampling probes for temperature and concentrations in catalytic reactors [2-10]. Such techniques were developed to gain better understanding of reactions as gas composition and temperature changes within a catalyst. These recent advances in sampling techniques offer previously unavailable insights in terms of kinetics and surface processes within the sample. The development of techniques using in-situ probes are providing the opportunity to bridge the "knowledge gap" between traditional catalyst effluent analysis and theories, and provide the additional information which is required to improve relevant simulations and models. However, there are several aspects in this evaluation of in-situ probes [1] which need to be examined in greater detail. 
Primarily, this paper was a CFD investigation of the invasiveness of in-situ probes, and its conclusions are substantially based on comparisons of CFD calculations with an intra-channel probe to CFD calculations in the absence of a probe. However, issues arise concerning the parameters used by Hettel et al. for the CFD modelling. Case A (centred in channel) is the most unlikely configuration, given the horizontal orientation of the monolith and considering the physical nature (flexible rather than rigid) and length of the capillary used with SpaciMS the capillary will inherently succumb to gravity. Therefore, cases C (centred on channel lower wall) and D (in a corner of the channel lower wall) exhibit more realistic configurations, given that the probes were positioned at the base of the channel. However, it should be noted that there is also a question regarding the modelling of cases $\mathrm{C}$ and D since the probe's shape has been varied compared with cases A and B (midway between the channel centre and corner), and as stated by Hettel et al. [1], this would change the cross-sectional area. Therefore, an accurate comparison is not possible with the work of Sá et al., even for cases C or D.

The veracity of the conclusions depends on the accuracy of the model, which is not demonstrated in the paper; even when opportunities exist via analysis of CFD trends or comparison to experimental measurements. For instance, while the trends in Tables 1 and 2 are qualitatively discussed as trending in a logical and consistent way, it is unclear if they quantitatively correlate. This type of analysis would be more correctly implemented via also reporting mass flow rates at the channel inlet where the composition is identical for the reference and probe channels The fact that this type of reporting, analysis and discussion was not included, suggests the paper could have benefited from more critical and thorough analysis of the CFD performance, particularly considering the similar level applied to other comparative works. Similar inconsistencies exist with respect to the comparison of the CFD and measurement results, which appear to similarly hinder the proposed broad conclusions regarding the invasive nature of intra-catalyst sampling. 
It is important to compare experimental data with the model; however, this has not been fully achieved in this study [1]. For example, in order to validate the scenario when there is no probe in the channel, the model should be compared with experimental data obtained through traditional catalyst-effluent analysis. A comparison of the model/simulations of flow/concentrations with experiments which use traditional effluent analysis should, therefore, also have been conducted rather than the assumption made that such models are correct. Moreover, comparison of such effluent and intra-catalyst measurements with respect to continuity at the catalyst exit could have provided critical assessment of the model results and the proposed conclusions.

There is only one reported figure (Fig 16) in Hettel et al. which reports a comparison between experimental and simulation data. From this figure, it is apparent that there are significant differences between the simulations and experimental results. This is particularly obvious in the trends for $\mathrm{H}_{2} \mathrm{O}$ and $\mathrm{CH}_{4}$ in the isothermal 0-4 mm range, with some smaller differences between simulation and experiment in the trend of oxygen. Indeed that analysis indicates that the experimental measurements are outside the "conservative" worst-case scenario bounds of the Case A model, which might hinder the proposed conclusions. Nevertheless, comparisons in the catalyst rear suggest a Case A capillary orientation which is contrary to the nature of these probes, and not substantiated by the authors with a statement of physical observation of how the capillary was in fact oriented. Given that there is such variation, enough ambiguity exists for this to be deemed inconclusive rather than critical or comprehensive.

Hettel et al. [1] stated that the work of Sá et al. [2], which also analysed the invasive nature of capillary probes used in SpaciMS applications, did not adequately describe the boundary conditions. The "Boundary conditions and parameters" section of Hettel et al. [1] included inlet velocity, inlet pressure, inlet temperature, mole fraction, suction rate and a fixed wall temperature as well as a reference to the Reynolds number. These same conditions are described in Sá et al. in terms of average inlet velocity, temperature, gas concentrations and outlet pressure (atmospheric), measured suction rate as well as the Reynolds number. The use of an identical volume flux of $200 \mathrm{~mL} \mathrm{~min}^{-1}$ at the entrance of all channels selected by Sá et al. can 
be justified by the laminar flow profile upstream of the monolith (pre-monolith section) with a maximum velocity at the centre of tube (ID $0.25 \mathrm{~mm}$ ) of $0.016 \mathrm{~m} / \mathrm{s}$. Since a monolith of $400 \mathrm{cpsi}$ was used (i.e. 19 channels along the diameter of tube), 3 x 3 empty channels will receive approximately similar volumetric flow rate. Similarly, Hettel et al. also assumed that the flow rates in the reference channels are similar (difference of 1\%). This is not necessarily the case if the channels are far from each other (unlike the 9 channels reported by Sá et al. which are located side by side).

Given these points, the CFD studies by both Hettel et al. and Sá et al. have used very similar parameterisation for the calculations, although the settings of these parameters vary due to the differences in operating conditions of the two systems. Because of significant differences in the physical setups used by Hettel et al. and Sá et al. and corresponding differences in the associated parameters, direct comparison of these two works cannot be drawn. For instance, it is apparent that the length of capillary used in Hettel et al. [1] is not the same as that used in Sá et al. [2]. This is primarily deduced from the gas suction rates reported by Hettel et al. since no details on the experimental set-up are provided and only a reference to Livio et al. [11] is given, which actually reports a suction rate of 0.5 to $1 \mathrm{~mL} / \mathrm{min}$ (vs. the $2 \mathrm{~mL} / \mathrm{min}$ in Hettel et al.) and does not contain specific information on capillary length either. Assuming that the maximum suction rate can be derived from the conductance equation which is dependent on the capillary length (see Equation 1) [9], some estimation of the probes length can be extracted.

$$
C_{v}=\left(136 * d^{4}\right) *(P / L)[\text { Equation 1] }
$$

where $C_{v}$ is conductance in $\mathrm{L} / \mathrm{s}$

$d$ is the diameter of the aperture in $\mathrm{cm}$

$P$ is the pressure difference from inlet to outlet in mbar

$L$ is the length of the capillary in $\mathrm{cm}$ 
The conditions reported by Hettel et al. [1] include a $2 \mathrm{~mL} / \mathrm{min}$ suction through a $170-\mu \mathrm{m}$ o.d. $\mathrm{x}$ $100-\mu \mathrm{m}$ i.d. capillary. Using the conductance equation it was determined that in order to achieve a suction rate of $2 \mathrm{~mL} / \mathrm{min}$ through a capillary of $100-\mu \mathrm{m}$ i.d., the maximum length of the capillary would be $40 \mathrm{~cm}$. Additionally, if one considers the suction rate of $5 \mathrm{~mL} / \mathrm{min}$ mentioned in section 5.1 .3 of Hettel et al. [1], the conductance equation would indicate that the maximum capillary length would be $\sim 16.5 \mathrm{~cm}$.

Furthermore, we believe that the conductance equation significantly over-estimates the suction rate through the capillary. This has been demonstrated experimentally on a number of occasions $[2,10]$. For example, with a $150-\mu \mathrm{m}$ o.d. x $80-\mu \mathrm{m}$ i.d. capillary of length $110 \mathrm{~cm}$, a suction rate derived from the conductance equation of $230 \mu \mathrm{L} / \mathrm{min}$ is calculated when the pressure difference is 1000 mbar [2]. However the experimentally determined value when such a capillary was placed in a monolith was found to be $4 \mu \mathrm{L} / \mathrm{min}$ [2]. Hence, in order to have an experimentally determined flow of $2 \mathrm{~mL} / \mathrm{min}$, a capillary significantly shorter than $40 \mathrm{~cm}$ (or shorter than $16.5 \mathrm{~cm}$ for suction of $5 \mathrm{~mL} / \mathrm{min}$ ) would have had to been used. The reactant gas flow rate reported by Hettel et al. also varies from that reported in Sá et al.; and, as Hettel et al. discuss, the smaller this initial velocity then the smaller the effect of the "blocking"/invasiveness by the probe [1]. Indeed, the 77,000 $\mathrm{hr}^{-1}$ space velocity (SV) used in this study may similarly represent a furthering of the "conservative" worst-case scenario regarding the invasive nature of the capillary; and while this SV may be applicable to the CPOX study, there are many other applications, at much lower SV values, where intra-catalyst measurements can provide critical insights.

These differences imply that, while there may be significant invasiveness of the probes under the conditions used by Hettel et al. this is not necessarily the case for the experimental setup used by Sá et al. [2] or any of the similar systems that use in-situ probes [3-10]. In fact, due to the variation of the set-ups, a direct comparison of Hettel et al. and Sá et al. is not possible, and for this reason the experimental and numerical data presented in Sá et al. cannot be deemed incorrect from the evidence provided in Hettel et al. Furthermore, it is unfortunate that the word 'falsification' or "falsified" was incorrectly used in reference to work using intra-catalyst probes, such as our work [2]. This word is typically used to imply intentional misleading, obfuscation or 
fabrication. It seems that Hettel et al. committed a language error, and may have intended to use words or phrases such as "bias due to the presence of the probe," "error," "offset," etc. Of course based on our thorough and careful analysis [2], we would disagree with even these characterizations. Certainly, and to be clear, neither our work referenced by Hettel et al., or any other of our individual, joint or otherwise work has ever involved falsification.

In conclusion, it is necessary to conduct evaluations of techniques which employ in-situ probes, but the conditions used for evaluation via modelling need to be explicitly described. Moreover, it is possible to design wholly experimental techniques which self-validate the invasive nature of intra-catalyst capillary sampling. Furthermore, due to the previously mentioned dependence of probe invasiveness on operating conditions, comparisons should only be drawn in the case of techniques which operate under similar conditions.

[ 1 ] M. Hettel, C. Diehm, B. Torkashvand, O. Deutschmann, Catal. Today, 2013, http://dx.doi.org/10.1016/j.cattod.2013.05.005.

[2] J. Sá, D.L. Abreu Fernandes, F. Aiouache, A. Goguet, C. Hardacre, D. Lundie, W. Naeem, W. P. Partridge, C. Stere, Analyst, 2010, 135, 2260.

[3] J.-S. Choi, W.P. Partridge, W.S. Epling, N.W. Currier, T.M. Yonushonis, Catal. Today, 2006, 114, 102.

[4] X. Auvray, W.P. Partridge, J.-S. Choi, J.A. Pihl, A. Yezerets, K. Kamasamudram, N.W., Currier, L. Olsson, App. Cat. B, 2012, 126, 144.

[5] J.-Y. Luo, X. Hou, P. Wijayakoon, S.J. Schmieg, W. Li, W.S. Epling, App. Cat. B, 2011, 102, 110.

[6] A. Abedi, J.-Y. Luo, W.S. Epling, Catal. Today, 2013, 207, 220

[7] R. Horn, O. Korup, M. Geske, U. Zavyalova, I. Oprea, R. Schlögl, Rev. Sci Instrum., 2010, $81,064102$.

[8] O. Korup, C.F. Goldsmith, G. Weinberg, M. Geske, T. Kandemir, R. Schlögl, R. Horn, J. Catal., 2013, 297, 1.

[9] J. Touitou, K. Morgan, R. Burch, C. Hardacre, A. Goguet, Catal. Sci. Tech., 2012, 2, 1811. [10] J. Touitou, R. Burch, C. Hardacre, A. Goguet, C. McManus, K. Morgan, J. Sá, Analyst, 2013, 138, 2858.

[11] D. Livio, C. Diehm, A. Donazzi, A. Berretta, O. Deutschmann, App. Cat. A., 2013, 467, 530. 